\title{
Cicatrización en Quemaduras Tipo AB-B en Conejillo de Indias (Cavia porcellus) Utilizando Miel de Ulmo Asociada a Vitamina C Oral
}

\author{
Healing of Burns Type AB-B in Guinea Pig (Cavia Porcellus) \\ Using Ulmo Honey Associated with Oral Vitamin C
}

\author{
"Carolina Schencke; "Jessica Salvo; ${ }^{* *}$ Carlos Veuthey; *Alejandra Hidalgo \& ${ }^{* * *}$ Mariano del Sol
}

\begin{abstract}
SCHENCKE, C.; SALVO, J.; VEUTHEY, C.; HIDALGO, A. \& DEL SOL, M. Cicatrización en quemaduras tipo AB-B utilizando miel de ulmo asociada a vitamina C oral. Int. J. Morphol., 29(1):69-75, 2011.

RESUMEN: En los últimos años se ha incrementado el interés por el uso de terapias alternativas para la curación de heridas. La miel de abeja es una antigua medicina natural que ha sido utilizada en el tratamiento de heridas y úlceras, mientras la vitamina $\mathrm{C}$ mejora la barrera epidérmica y reduce la contracción de heridas. Este estudio pretende avalar el tratamiento con miel asociada a vitamina $\mathrm{C}$ oral como curación alternativa y eficiente en quemaduras tipo AB-B. Se utilizaron 12 cuyes (Cavia porcellus). Los animales se distribuyeron en grupos A ( $\sin$ Vitamina C) y B (con Vitamina C). Bajo efectos anestésicos se provocó una quemadura de $1.7 \mathrm{~mm}$ de diámetro en la región dorsal derecha, que fue tratada con curaciones con miel. Al mismo tiempo, se provocó una quemadura de similares características en la región dorsal izquierda, tratada con suero Ringer, siendo utilizada como control. De ambas lesiones se obtuvieron biopsias a los 6, 10 y 14 días post injuria. Nuestros resultados muestran que la formación de tejido granular, activación de fibroblastos, y reepitelización es más rápida en el grupo $\mathrm{B}$, donde se observó un tejido vascularizado y fibras colágenas organizadas en el día 14 post injuria, similar al control (biopsia de animal sano). Estos datos confirman que la utilización de la miel de ulmo asociada a Vitamina C oral mejora la regenaración de este tipo de heridas, logrando una cicatrización efectiva, rápida y de buena calidad.
\end{abstract}

PALABRAS CLAVE: Quemaduras; Miel; Vitamina C; Conejillo de Indias.

\section{INTRODUCCIÓN}

En los últimos años se ha incrementado el interés por el uso de terapias alternativas para la curación de heridas. La miel de abeja es una antigua medicina natural que fue utilizada en el tratamiento de heridas y úlceras, siendo luego reemplazada por el uso de antibióticos. Sin embargo, la aparición de resistencias bacterianas a los antibióticos ha llevado a reevaluar este tratamiento. Actualmente, la evidencia científica valida la miel y sus derivados por su efecto sobre 60 especies bacterianas incluyendo aerobios y anaerobios, Gram positivos y negativos (Estrada et al., 2005; Lay-flurrie, 2008). Vardi et al. (1998) analizaron los resultados de la aplicación de la miel, en el tratamiento de heridas postquirúrgicas infectadas de nueve neonatos, que no respondían al tratamiento convencional con antibióticos, obteniendo resultados positivos en su actividad antimicrobiana.
Se han realizado estudios en tratamientos de úlcera venosa (Gethin \& Seamus, 2008) y en heridas necróticas donde se ha demostrado su acción debridante, por lograr la conversión de plasminógeno en plasmina, que se suma a sus propiedades acidificante y osmolaridad, Molan (2001). Su actividad se ha evaluado en gasas impregnadas con miel, siendo efectivas, seguras y prácticas de aplicar (Aykut et al., 2003). Estudios del efecto de la miel en cicatrización de heridas han sido ampliamente analizados (Oryan \& Zaker, 1998; Bowler, 2002; Ghaderi, et al., 2010). Buratti et al., (2007) evaluaron la capacidad antioxidante de la miel. La enzima glucosa oxidasa actúa convirtiendo glucosa en glucosa ácida, y por la acción de microorganismos que no logran sobrevivir en el medio ácido, se genera un proceso que libera peróxido de hidrógeno (Evans \& Flavin, 2008). Bang

\footnotetext{
Facultad de Ciencias de la Salud, Universidad Autónoma de Chile, Temuco, Chile.

** Facultad de Medicina Veterinaria, Universidad Mayor, Temuco, Chile.

**** Facultad de Medicina, Universidad de La Frontera, Temuco, Chile.
} 
et al., (2003), midieron concentraciones de peróxido de hidrógeno en distintas diluciones de miel y sus implicancias en el tratamiento de heridas. Las concentraciones de peróxido de hidrógeno generadas son 0,003\%, aproximadamente 1000 veces menos potente que lo usado convencionalmente (solución al 3\%) logrando una acción citotóxica baja.

La capacidad de la miel también se ha medido en relación a la producción de citoquinas. Tonks et al., (2003), estudiaron el efecto de tres tipos de miel en la liberación de citoquinas por la línea monocítica MM6 (monoMac-6). Todas las mieles indujeron la liberación de factor tumoral alfa, IL-1B e IL-6 de las células MM6, líneas celulares directamente involucradas en la regeneración de tejidos. El factor tumoral es una citoquina de acción pro-inflamatoria, que genera quimiotaxis en macrófagos y promueve su activación. Estimula la angiogénesis, proliferación fibroblástica y la síntesis de prostaglandinas y colagenasa por fibroblastos. Actualmente, se han realizado mediciones de los valores nutricional y medicinal de la miel (Cizmarik et al., 2004; Khan et al., 2007; Ureña et al., 2007). La composición de la miel es: agua (17\%), azúcares (80\%) en la forma de glucosa y fructosa, además de proteínas, ácidos grasos, minerales traza, vitaminas y enzimas.

Estudios demuestran que el estado nutricional es fundamental en pacientes con heridas por segunda intención. La regeneración requiere de elementos esenciales para su reparación y correcta cicatrización. El estrés asociado a una lesión resulta en una mayor necesidad de vitamina C. Stotts et al., (1990), analizaron noventa adultos de 65 años de edad promedio, con heridas por segunda intención, donde la gran mayoría presentó una baja en los valores plasmáticos de vitaminas y minerales, principalmente de Vitamina $\mathrm{C}$ y solo un $1 \%$ presento bajas de zinc. La vitamina $\mathrm{C}$ es requerida para la síntesis de colágeno y angiogénesis. Rasik \& Shucla (2000), demuestran que niveles adecuados de antioxidantes como, catalasa y vitamina $\mathrm{C}$ y $\mathrm{E}$, juegan un papel crucial en la regeneración de heridas, especialmente en ratas diabéticas, o con lesiones al hígado y páncreas e inmunodeprimidos. Los mamíferos generan su propia vitamina $\mathrm{C}$, excepto humanos, primates y conejillo de indias (Cavia porcellus). Un animal puede generar $13 \mathrm{~g}$ de vitamina $\mathrm{C}$, casi 200 veces lo requerido por la FDA, y en estado de estrés pueden aumentar en 10 veces sus propios valores normales, lo que no es posible en humanos. Nuestra piel sufre con la exposición al sol, polución y cigarro, situaciones que disminuyen los niveles de vitamina C. La exposición UV de 1,6 MED disminuye los valores de vitamina C en un 70\% bajo el nivel normal. Según Burke (2004), el uso tópico de vitamina $\mathrm{C}$ tiene un alto poder antiinflamatorio $\mathrm{y}$ estimula directamente la síntesis de fibras colágenas. Esta vitamina es un esencial cofactor en las enzimas requeridas para la síntesis de colágeno, como hidrolyl hidroxylasa y lisil hidroxilasa. Bajo efectos del ácido ascórbico, los fibroblastos aumentan su proliferación en 4 veces y éstos aumentan su síntesis de vitamina $\mathrm{C}$.

El efecto antioxidante de la vitamina $\mathrm{C}$ ha sido ampliamente estudiado, no sólo reacciona con radicales libres, también actúa restaurando las propiedades antioxidantes de la vitamina E. Las consecuencias de sus actividades antioxidantes incluyen el control y mantención de la membrana celular y organelos, incluyendo además una acción protectora de células fagocíticas (Bendich et al., 1986). Boyce et al., (2002) confirman que la vitamina $C$ promueve la proliferación de fibroblastos, síntesis de ADN y metabolismo mitocondrial. Además, estimula el desarrollo de la membrana basal, reduciendo la contracción de la herida. La deficiencia de vitamina $\mathrm{C}$ causa un bloqueo directo en la barrera epidermal generada por los queratinocitos. Luego de una quemadura, bajan los niveles de ATP, y se incrementan los de AMP, lo que promueve la formación del sustrato xantina oxidasa. Estas reacciones generan peróxido de hidrógeno y superóxido, promoviendo altas concentraciones de radicales libres. La terapia antioxidante recomendada por Horton, 2003, glutatión y vitaminas C, A, y E, reduce la posibilidad de un shock séptico por quemadura, atenúa los cambios en el metabolismo celular, y protege la circulación microvascular. Horton confirma que el estrés oxidativo generado por la quemadura se puede detener con estrategias que inhiban la formación de radicales libres. Los estudios mencionados demuestran beneficiosos efectos del uso tópico de la miel y de la vitamina $\mathrm{C}$ en la cicatrización de heridas en general, sin embargo, no se han descrito estudios sobre el efecto de la miel en quemaduras, o de la utilización de ambos tratamientos asociados. Este estudio pretende evaluar morfológicamente el efecto del tratamiento de miel de ulmo asociada a vitamina $C$ oral como curación alternativa y eficiente en quemaduras tipo AB-B en conejillo de indias (Cavia porcellus).

\section{MATERIAL Y MÉTODO}

Se utilizaron 12 conejillos de indias (Cavia porcellus). Los animales se distribuyeron en grupo A (tratamiento con miel, sin Vitamina C) y grupo B (tratamiento con miel mas Vitamina $\mathrm{C}$ oral). Bajo efectos anestésicos se provocó una quemadura de $0,7 \mathrm{~cm}$ de diámetro en el lomo derecho, que fue tratada con curaciones con miel. Al mismo tiempo se provocó una quemadura de similares características en el lomo izquierdo, tratada con suero Ringer, siendo utilizada como control. Ambos grupos de animales fueron anestesiados utilizando como protocolo anestésico 
una asociación medicamentosa de Ketamina, Xilacina y Atropina en dosis de $40 \mathrm{mg} / \mathrm{kg} ; 5 \mathrm{mg} / \mathrm{kg}$ y $0.05 \mathrm{mg} / \mathrm{kg}$ de peso vivo respectivamente. Una vez anestesiados, se realizó la depilación en la zona del lomo posterior al cuello para generar la quemadura con un objeto metálico caliente, generando una lesión de una extensión aproximada de $0,7 \mathrm{~cm}$, por un tiempo cronometrado de 3 segundos en el lomo izquierdo y derecho.

Posterior a la injuria y con el animal anestesiado, se realizó la curación en el lomo derecho, aplicando una gasa estéril impregnada en miel de ulmo en la región comprometida, dos veces al día hasta la obtención de la biopsia. En el lomo izquierdo se realizaron dos curaciones al día sólo con suero fisiológico, el que fue ocupado como control del tratamiento. La extracción de la biopsia se realizó bajo anestesia general utilizando el mismo protocolo anestésico, tomando una muestra de tejido profunda que abarcó epidermis, dermis, hipodermis, y parte de tejido muscular de ambos lados donde se produjo la injuria. Posteriormente, se suturaron los bordes de la herida con puntos separados, protegiendo la herida con apósito estéril y un vendaje suave.

De ambas quemaduras se obtuvieron biopsias a los 6, 10 y 14 días post injuria, las que fueron depositadas en recipientes con formalina al 10\% tamponada con buffer. Las muestras fueron procesadas, deshidratadas en batería de alcoholes e incluidas en paraplast. Posteriormente, se realizaron cortes seriados de $7 \mu \mathrm{m}$ hasta llegar a la zona de la injuria, zona cortada en $5 \mu \mathrm{m}$ de espesor. Las muestras histológicas fueron teñidas con hematoxilina - eosina para la descripción histológica y tricrómico de Masson para observar la presencia de fibras colágenas. Para el estudio morfológico y obtención de fotografías se utilizó un microscopio Carl Zeiss, Axiolab, con cámara Mc80 DX.

\section{RESULTADOS}

El conejillo de indias (Cavia porcellus) presenta en la biopsia normal un estrato córneo delgado. La región mas superficial de la dermis presenta un tejido conjuntivo laxo, en tanto la capa profunda presenta un tejido conjuntivo denso con folículos pilosos y glándulas sudoríparas (Fig. 1.A). La biopsia del animal de prueba, quemado en el lomo por 3 segundos, evidenció que el daño se generó hasta la capa démica profunda (Fig. 1.B).

Grupo A (con miel, sin vitamina C oral). En el día 6 post injuria, la biopsia control no presentó regeneración a nivel de la capa epidérmica, presentando tejido granular y forma-
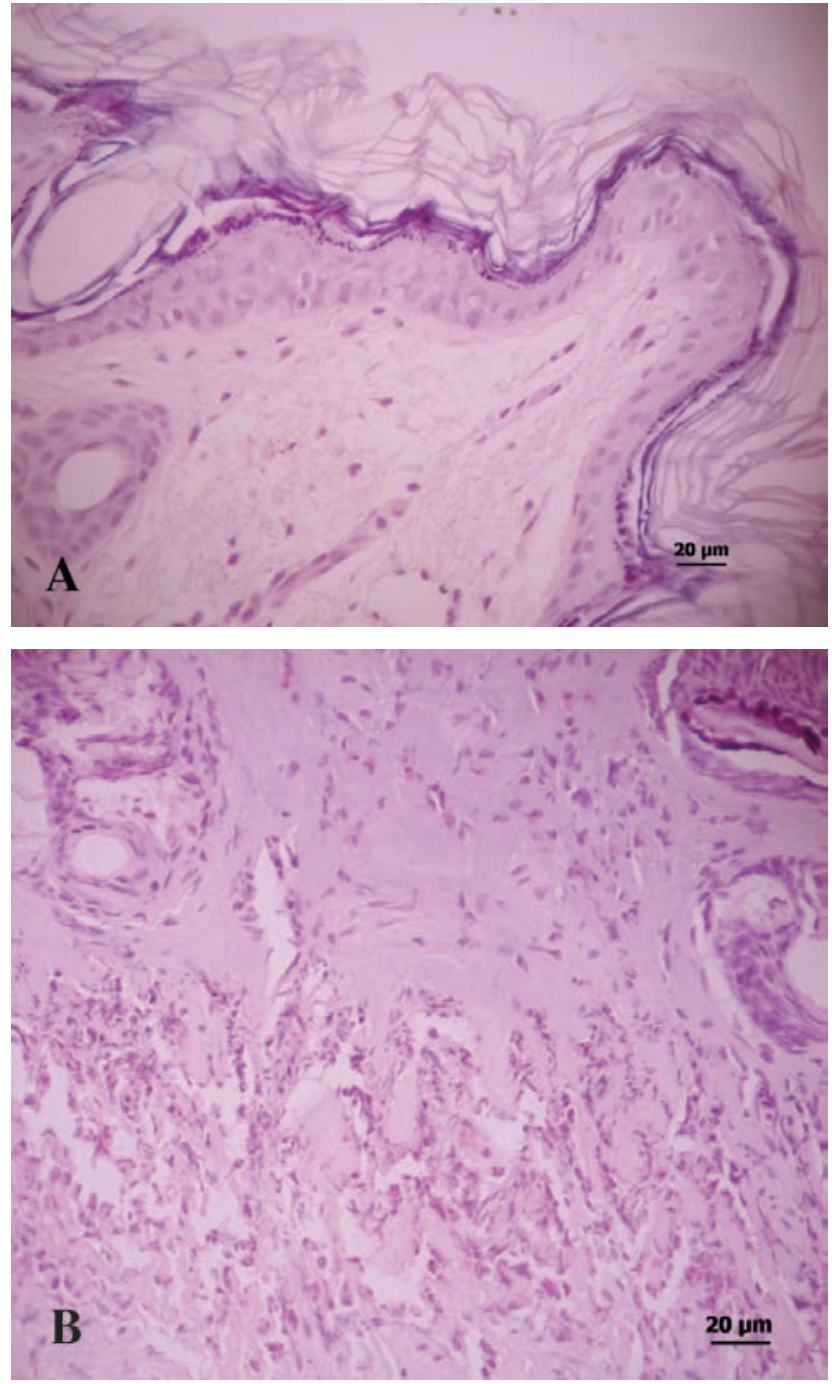

Fig. 1. A. Biopsia normal de conejillo de indias (Cavia porcellus). La región mas superficial de la dermis presenta un tejido conjuntivo laxo (flecha), tinción H.E. B. Biopsia de animal de prueba, quemado por 3 segundos, realizada por 24 horas post quemadura. Se observan las capas epidérmica y dérmica con presencia de edema y tejido granular.

ción de edema (Fig. 2.A). La biopsia obtenida de la zona tratada presentó tejido granular, fibroblastos activos, células polimorfonucleadas (PMN) y leve formación de edema en la capa dérmica. Se observó presencia de fibras colágenas, presentes en un tejido conjuntivo denso irregular. En la epidermis aún no se observa regeneración (Fig. 2.B).

En el día 10 post injuria, la biopsia control no ha regenerado la capa epidermal, presentando tejido granular y edema (Fig. 3. A). L a biopsia exttraida de la zona tratada presentó una capa epidérmica gruesa, con una delgada capa de queratina en la superficie. La presencia de membrana 

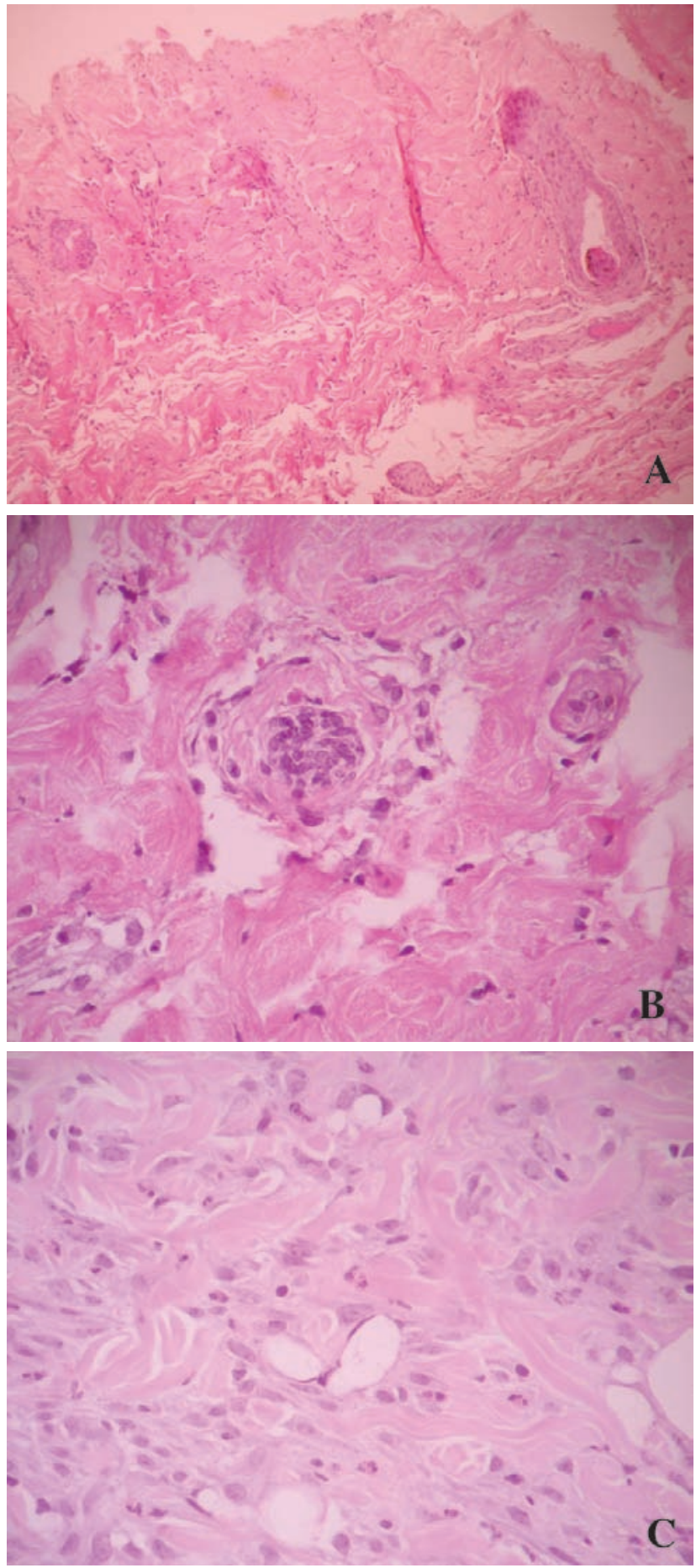

Fig. 2. Biopsias del día 6 post injuria en conejillo de indias (Cavia porcellus), tinción H.E. A. Biopsia control. No se ha regenerado la capa epidermal, presenta tejido granular y formación de edema. B. Biopsia obtenida del grupo tratado con miel. La dermis presenta tejido granular, fibroblastos activos, células polimorfonucleadas, (PMN) y leve formación de edema. C. Biopsia obtenida del grupo tratado con miel asociada a vitamina C. No se observa la capa epidérmica. En la dermis hay presencia de PMN, con fibroblastos activos, presentando un núcleo ovoide, ligeramente aplanado.
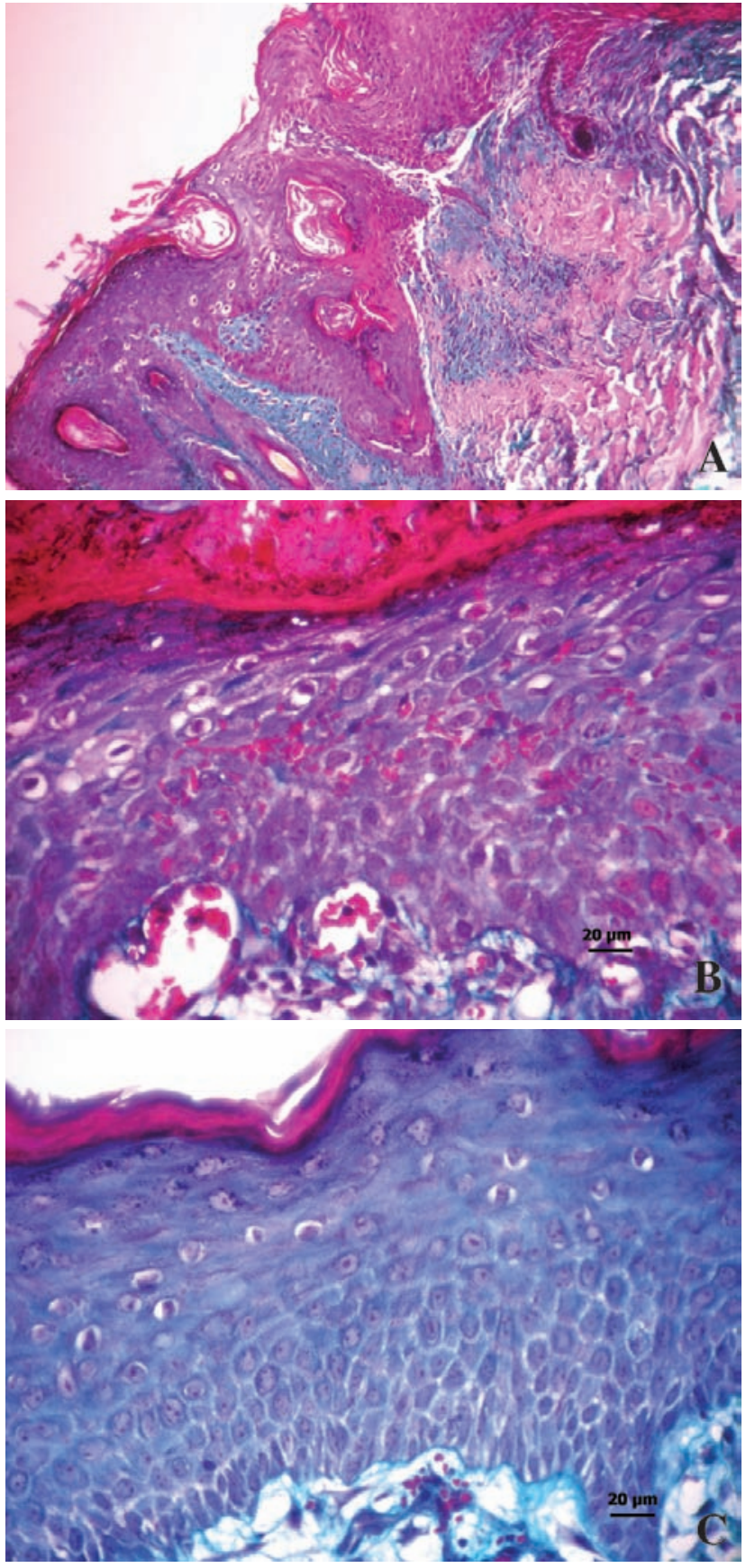

Fig. 3. Biopsias del día 10 post injuria en conejillo de indias $(\mathrm{Ca}$ via porcellus), tinción tricrómico de Masson. A Biopsia control. Presenta epitelización imperfecta, epidermis irregular, dermis con evidente formación de edema, alto porcentaje de PMN. B. Biopsia obtenida del grupo tratado con miel. La membrana basal es poco evidente con leve presencia de edema (flecha). La epidermis está cubierta de una delgada capa de queratina. Hacia el lumen se observa parte de la escara. C. Biopsia obtenida del grupo tratado con miel asociada a vitamina C. En la dermis se normaliza la población de fibroblastos, las fibras colágenas se encuentran organizadas. La capa epidérmica se presenta como una gruesa capa queratinizada y se evidencia la membrana basal. 
basal aún no es evidente (Fig. 3.B). La capa dérmica presenta tejido conjuntivo laxo con fibras colágenas, leve formación de edema, escaso tejido granular, y neoformación de vasos sanguíneos (Fig. 4.A).

En el día 14 post injuria, la biopsia control presentó reepitelización imperfecta y una dermis irregular. La dermis presentó una evidente formación de edema, alto porcentaje de PMN, y fibras colágenas desorganizadas (Fig. 5.A). Las biopsias de animales tratados con miel de ulmo presentaron una dermis con fibras colágenas organizadas, sin presencia de PMN, tejido granular, ni edema. La epidermis presentó formación de algunas capas de queratina; sin embargo, el número de capas de queratinocitos a lo largo del tejido varió, presentando una epidermis irregular (Fig. 5.B).
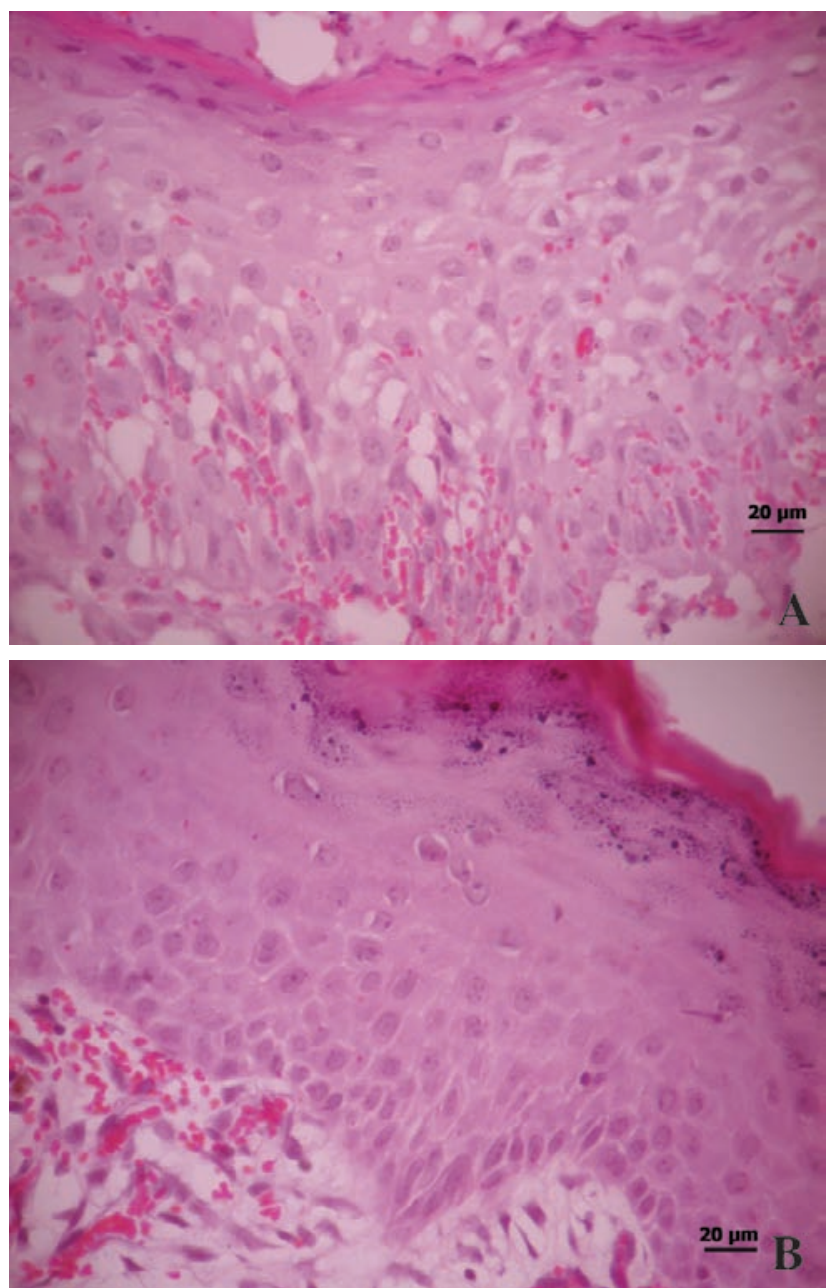

Fig. 4. Biopsias del día 14 post injuria en conejillo de indias $(\mathrm{Ca}$ via porcellus), tinción H.E. A. Biopsia obtenida del grupo tratado con miel. Se observa neoformación de vasos sanguineos, tanto en la dermis como en la epidermis. B. Biopsia obtenida del grupo tratado con miel asociado a vitamina $\mathrm{C}$ oral. Los vasos sanguíneos se ubican en la dermis, sin presencia de edema (flecha).
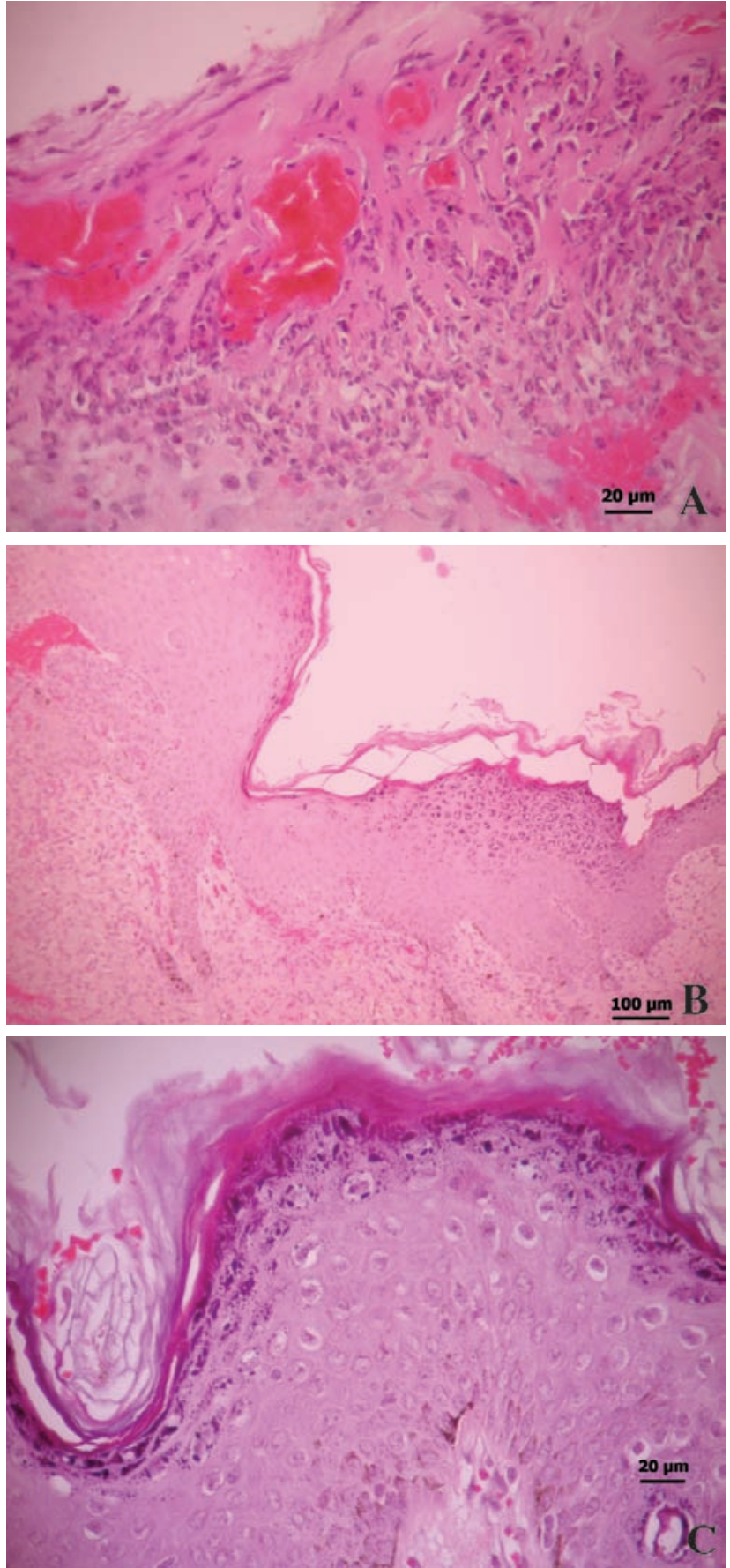

Fig. 5. Biopsias del día 14 post injuria en conejillo de indias (Cavia porcellus), tinción H.E. A. Biopsia control. La epidermis no se ha regenerado, presentando edema y vasos sanguíneos. La dermis presenta un tejido pobre en fibras colágenas, y escasa presencia de fibroblastos. B. Biopsia obtenida del grupo tratado con miel. La dermis presenta gran densidad de fibras colágenas. La epidermis es gruesa e irregular. Se evidencia la formación de queratina. C. Biopsia obtenida del grupo tratado con miel asociado a vitamina C. Presenta una capa epidérmica gruesa, queratinizada. Hacia el lumen se observan alguno glóbulos rojos pertenecientes a restos de la escara (flecha). Se observan melanocitos en el estrato basal. 
Grupo B (con miel de ulmo asociada a vitamina C oral).

En el día 6 post injuria la biopsia no presenta regeneración epidermal. En la dermis se observó la presencia de PMN, y fibroblastos activos con núcleo ovoide, ligeramente aplanado. Hay gran densidad de fibras colágenas dispersas en la matriz y leve formación de edema. (Fig. 2.C).

En el día 10 post injuria disminuye la población de fibroblastos. Las fibras colágenas se encuentran organizadas en la dermis, presentando tejido conjuntivo laxo irregular bajo la capa epidérmica. La epidermis se presenta como una capa gruesa, con queratinización leve. La membrana basal está presente (Fig. 3.C). Se observó neoformación de vasos sanguíneos en la capa dérmica superficial (Fi. 4.B).

En el día 14 post injuria se observa una capa epidérmica gruesa, la que presenta queratinización en la superficie de la lesión, donde aún se observan algunos glóbulos rojos pertenecientes a restos de la escara. Se observan claramente melanocitos en el estrato basal. La dermis está correctamente organizada, con glándulas sebáceas y folículos pilosos. (Fig. 5.C).

\section{DISCUSIÓN}

Los resultados presentados en este estudio entregan una valiosa información sobre el tratamiento en quemaduras con miel de ulmo asociada a vitamina $\mathrm{C}$ oral. El solo uso de miel de ulmo disminuye la posibilidad de infección, inflamación y edema, demostrando rapidez en la cicatrización al compararla con el control, el cual al día 14 post quemadura aún no presenta regeneración de la barrera epidermal, presentando un evidente estado inflamatorio; sin embargo, la formación de tejido granular, activación de fibroblastos, producción de fibras colágenas, regeneración de la barrera epidermal y queratinización es más rápida y de mejor calidad en la terapia asociada a la vitamina $\mathrm{C}$ oral. Nuestros resultados concuerdan con estudios realizados en cicatrización de heridas con miel (Vardi; Oryan \& Zaker; Bowler; Aykut et al.; Molan; Estrada et al.; Lay-flurrie; Gethin \& Seamus; Ghaderi). La miel presenta capacidad antioxidante (Buratti et al.; Evans \& Flavin y Bang et al.), además de activar la línea monocítica, liberación de citoquinas, factor tumoral alfa e interleucinas (Tonks et al.). Si a estas cualidades de la miel le sumamos los beneficios de la vitamina $\mathrm{C}$, con un alto poder antiinflamatorio, estimulación directa de la síntesis de fibras colágenas, aumento de la proliferación de fibroblastos en 4 veces (Burke, 2004; Boyce et al.), se podría inferir que este tratamiento mixto de miel asociado a vitamina $\mathrm{C}$ aporta un doble beneficio. Su contribución en la cicatrización de la quemadura en conejillo de indias (Cavia porcellus), fue lograr una mejor morfogénesis de la barrera epidermal, proliferación de fibroblastos, estimular el desarrollo de la membrana basal, neoformación de vasos sanguíneos y síntesis de queratinocitos. De esta manera se logró promover rápidamente el cierre de la herida provocada por la quemadura.

El estado nutricional es fundamental en pacientes con heridas por segunda intención. Según Stotts et al., la gravedad de la lesión incrementa la necesidad de vitamina C. Otros nutrientes necesarios para la regeneración, como son las vitaminas A, B, E, D y K no han presentado deficiencia en pacientes malnutridos, ya que se almacenan en el organismo por algún tiempo. El zinc y hierro son elementos importantes en la formación de colágeno, sin embargo, la deficiencia de zinc es rara y la de hierro se observa en situaciones específicas. Si a esto le sumamos el poder antioxidante (Bendich $e t$ al.; Rasik \& Shucla; Horton), podríamos concluir que la necesidad de la administración diaria de la vitamina $C$ vía oral se manifiesta no solo en pacientes quemados, sino también en heridas de pacientes con patologías hepáticas, pancreáticas, diabéticos, inmunodeprimidos o simplemente con problemas de malnutrición.

La miel es un producto de un alto valor nutricional, (Cizmarik et al.; Khan et al.; Ureña et al.), sin embargo, no existe en Chile como un producto de aplicación clínica para uso tópico en heridas. La miel comercial podría perder algunos de sus beneficios en el proceso de esterilización. En nuestros resultados la miel logra estimular la rápida regeneración de la barrera epidermal; sin embargo, la miel de ulmo por sí sola, no logra equiparar los resultados obtenidos con el tratamiento asociado a vitamina $\mathrm{C}$ oral.

SCHENCKE, C.; SALVO, J.; VEUTHEY, C.; HIDALGO, A. \& DEL SOL, M. Healing of burns type AB-B in guinea pig (Cavia porcellus) using Ulmo Honey associated with oral vitamin C. Int. J. Morphol., 29(1):69-75, 2011.

SUMMARY: In recent years there has been increasing interest in the use of alternative therapies for healing wounds. Bee honey is an ancient natural medicine that has been used in the treatment of wounds and ulcers, while Vitamin C improves the epidermal barrier and reduces wound contraction. The aim of this study is to support treatment with honey associated with oral vitamin $\mathrm{C}$ as an alternative and efficient healing treatment, in type AB-B burns. For this study, twelve guinea pigs (Cavia porcellus) were used. The animals were distributed in groups A (without Vitamin C) and B (with Vitamin C). While under anesthetic effect burn of $1.7 \mathrm{~mm}$ in diameter was caused in the right dorsal region, subsequent healing was treated with honey. At the same time a burn of similar characteristics was caused in the left dorsal region, treated with Ringer serum being used as control. Biopsies were obtained from both lesions at days 6,10 and 14 post injury. Results showed granular 
tissue formation, fibroblast activation, and reepitalization is more rapid in group B, where vascularized tissue and organized collagen fibers were observed at day 14 post injury similar to control (biopsy in healthy animal). These results confirm that the use of Ulmo honey associated with oral Vitamin $\mathrm{C}$ improves regeneration in this type of wound, achieving effective, rapid and good quality healing.

KEY WORDS: Burns; Ulmo honey; Vitamin C; Guinea pig.

\section{REFERENCIAS BIBLIOGRÁFICAS}

Aykut, M.; Eroglu, S.; Karacaoglan, N.; Akan, M.; Akoz, T. \& Yildrim, S. Use of honey as an adjunct in the healing of splitthickness skin graft donors site. Dermatol. Surg., 29(2): 16872,2003

Bang, L.; Bunting C. \& Molan, P. The effect of dilution on the rate of hydrogen peroxide production in honey and its implications for wound healing. T. J. of Alt. and Compl. Med., 9(2):267-73, 2003.

Bendich, A.; Machlin, L. J.; Scadura, O.; Burton, G. \& Wayner, D. The antioxidant role of vitamin C. Advances in Free Radical Biology \& Medicine, 2(2):419-44, 1986.

Boyce, S.; Supp, A.; Swope, V. \& Warden, D. Vitamin C regulates keratinocyte viability, epidermal barrier, and basement membrane in vitro, and reduces wound contraction after grafting of cultured skin substitutes. J. Invest. Dermatol., 118:565-72, 2002.

Bowler, P. Wound pathophysiology, infection and therapeutic options. Ann Med., 34:419-27, 2002.

Burke, K. Photodamage of the skin: protection and reversal with topical antioxidants. J. Cosmet. Dermatol., 3:149-55, 2004.

Buratti, S.; Benedetti, S. \& Cosio. Evaluation of the antioxidant power of honey, propolis and royal jelly by amperometric flow injection analysis. Talanta, 71:1387-92, 2007.

Chicas, J. Tiempo de cicatrización por segunda intención de piel, en ratas bajo tratamiento con dexametasona; comparando la criocirugía con la cirugía convencional. Tesis presentada para la obtención del título de Médico Cirujano. Facultad de Medicina. Universidad Francisco Marroquin, 2004.

Cizmarik, J.; Hrobonova, K. \&Lehotay, J. Determination of monosaccharides and disaccharides in honey. Acta Facultatis Pharmaceuticae, 1:73-5, 2004.

Estrada, H.; Gamboa, M.; Chaves, C. \& Arias, M. Alan. 55(2):167$71,2005$.

Evans \& Flavin. Honey: a guide for healthcare professionals. British Journal of Nursing, 17(15):24-30, 2008.
Gethin, G \& Seamus, C. Manuka honey vs. Hydrogel-a prospective, open label, multicentre, randomised contrlled trial to compare desloughing efficacy and healing outcomes in venous ulcers. J. of Clinical Nursing, 18:466-74, 2008.

Ghaderi, R.; Afshar, M.; Akhbarie, H. \& Jafar, M. Comparison of the efficacy honey an d animal oil in accelerating healing of full thickness wound of mice skin. Int. J. Morphol., 28(1):19398, 2010

Horton, W. Free radicals and lipid peroxidation mediated injury in burn trauma: The role of antioxidant therapy. Toxicology, 189(1-2):75-88, 2003.

Khan, F.; Abadin, U. \& Rauf, N. Honey: Nutritional and medicinal value. Int. J. Clin. Pract., 61(10):1705-07, 2007.

Lay-flurrie. Honey in wound care: effects, clinical application and patient Benedit. British Journal of Nursing, 2008.

Molan, P. C. Why honeey is effective as a medicine. 2. The scientific explanation of its effects. Bee. World, 82(1):22-40, 2001.

Oryan, A. \& Zaker, R. Effect of topical application of honey on cutaneus wound healing in rabbits. J. Vet. Med. 45:181-88, 1998.

Rasik, A. \& Shucla, A. Antioxidant status in delayed healing type of wounds. Int. J. Path., 81:257-63, 2000.

Stotts, N. \& Whitney, J. Nutritional intake and status of clients in the home with open surgical wounds. J. of Community Health Nursing, 7(2):77-86, 1990.

Tonks, A.; Cooper, R.; Jones, K.; Blair, S.; Parton, J. \& Tonks, A. Cytokine, 21:242-47, 2003.

Ureña, V.; Arrieta, E.; Umaña, E.; Zamora, L. \& Arias, M. evaluacion de la posible adulteración de mieles de abeja comerciales de origen costarricense al compararlas con mieles artesanales provenientes de apiarios específicos. Archivos Latinoamericanos de Nutricion, 57(1):63-6, 2007.

Vardi, A.; Barzilay, Z.; Linder, N.; Cohen, H.; Paret, G. \& Barzilai, A. Local application of honey for treatment of neonatal postoperative wound infection. Acta Pediatr., 87:429-32, 1998.

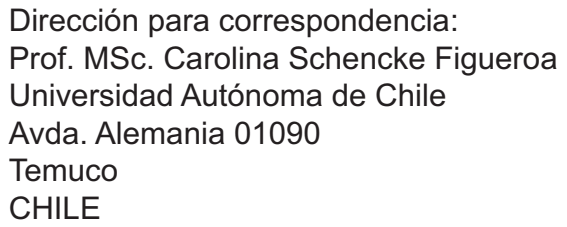

Dirección para correspondencia:

Prof. MSc. Carolina Schencke Figueroa

Universidad Autónoma de Chile

Avda. Alemania 01090

Temuco

CHILE

Email: carolina.schencke@uautonoma.cl

Recibido : 19-09-2010

Aceptado: 22-11-2010 